\title{
Changes in the Association Between Education and Cohabitation in Post-reform China Wei Wang, Man-Yee Kan
}

\begin{abstract}
This paper examines the relationship between educational attainment and premarital cohabitation among married individuals in post-reform China. Premarital cohabitation has increased dramatically in China in the last few decades. Past studies have suggested that education is positively associated with premarital cohabitation in China, but how this association changes over time when cohabitation grows from a marginal phenomenon to a popular choice remains unknown. This paper investigates the changes in the association between education and premarital cohabitation in China. Using longitudinal data from the China Family Panel Studies (2010-2016), logistic regressions are carried out to compare the association between education and premarital cohabitation across three marriage cohorts: 1981-1992, 1993-2001, 2002-2016. Results show that opposite to trends in many Western countries, the positive association between education and premarital cohabitation has not decreased but instead strengthened over time in China. This trend is more consistent for women than men. The findings suggest that China is developing different patterns and trends of demographical changes because of its unique institutional and cultural context.
\end{abstract}




\section{INTRODUCTION}

Cohabitation has become an increasingly common stage before marriage in post-reform China. As educational attainment is an important indicator of economic prospect, social status, and cultural characteristics, the identification of the association between education and cohabitation is essential for deepening the understanding of the essence and features of cohabitation in a given society. The aim of this paper is thus to explore the association between educational attainment and premarital cohabitation among married individuals in post-reform China (after 1978), with a particular focus on the historical development of this association over the past few decades. This paper will first introduce the theoretical framework and empirical evidence regarding education and cohabitation in Western countries, which will be followed by a discussion around the contextual difference of China, with respect to the institutional and cultural changes related to cohabitation and education.

Family patterns have experienced dramatic changes in the last century throughout the world. Many Western developed countries have witnessed demographic changes featuring sub-replacement fertility, alternative arrangements of marriage, higher divorce rate, genderegalitarian relationships, births out of wedlock, and declining population size. This has been summarised by some scholars as the "second demographic transition" (Lesthaeghe, 2010). Of particular importance is the phenomenon of cohabitation, meaning co-residing without being legally married, which has increased dramatically over the last 50 years. For example, the percentage of marriages preceded by cohabitation grew from $10 \%$ in the 1960 s to over $50 \%$ in the 1990s in the United States (Bumpass \& Lu, 2000; Smock, 2000). Regardless of national variations, an increasing trend has been observed among European nations in general, with Nordic countries taking the lead. The proportion of cohabiting couples among those in any partnership for people aged between 25 and 34 in 2001 reached $85 \%$ in Sweden and was above $70 \%$ in both Finland and Denmark (Kiernan, 2004). In East Asian countries 
such as Japan, similar trends were found as well. For the same age group (25-34), 25\% of females were reported to have had cohabitation experience in a national survey in Japan in 2004 (Raymo et al., 2009). These findings indicate that a fundamental change in intimate relationships and family formation might have occurred all around the world (Rindfuss \& VanderHeuvel, 1990). Much of the previous research on cohabitation has focused on the characteristics of cohabitors, and the results were inconclusive. While the majority of the literature has found that cohabitors tend to be less-educated (Thornton et al., 1995; Bumpass et al., 1991; Bumpass \& Lu, 2000), others have found variations amongst different countries, or over time within the same country (Thomson \& Bernhardt, 2010).

In China, although cohabitation is a relatively new phenomenon, it has experienced a significant increase over the past few decades after the economic reform started in the late 1970s. The proportion of couples cohabiting before marriage was only around $10 \%$ in the 1970s, and this figure was found to be nearly one third in the recent marriage cohort (Yu \& Xie, 2015). However, there are fundamental differences between cohabitation in China and Western developed countries. One major difference is that fertility is very rare in the state of cohabiting in China, contrasting with that in Western countries where a delinking of procreation and marriage has been witnessed (Cherlin, 2004). For instance, half of all out-ofwedlock births occur in cohabiting relationships in the United States (Bumpass et al., 1991; Heuveline \& Timberlake, 2004), whereas fertility remains an activity that is tightly restricted within marriage in China. This seems to link with current legislation in China that require women to be married to get the 'birth permit' before giving birth to children, which is crucial for ensuring that the child can be registered with the House Registration System (Hukou) ${ }^{1}$

\footnotetext{
${ }^{1}$ Hukou system was set up in 1951 as a monitoring mechanism of population movement, which restrains individual rights such as entitlement to education, employment and social welfare to a specified locality (Chan \& Zhang, 1999).
} 
and be entitled to the benefit of the state schools and social welfare system (Currier, 2008). As a result, this regulation renders the out-of-wedlock birth rate extremely low and childbearing continues to be predominantly restricted within marriage. Unlike Western countries, where cohabitation increasingly resembles a family status (Bumpass et al., 1991), and marriage has gradually been deinstitutionalised and reduced to "a prestigious form of symbolic capital" (Cherlin, 2004) or "one life-style among others" (Giddens, 1992), marriage persists as the primary institution in China. In this context, cohabitation seems to function as a transitional stage before marriage rather than substituting for marriage.

Therefore, the low fertility in cohabitating relationships in China reflects a deeper institutional difference between Chinese and Western societies. Contrary to cohabitation appearing as an individual choice in many Western developed countries, cohabitation in China occurs under the strong influence of the State through its laws and regulations regarding marriage and fertility. Thus, cohabitation is not an entirely personal choice in China, but an outcome of individuals navigating their family choices under the shaping force of a strong state.

Despite a large volume of research on cohabitation in Western countries, there has been little research on cohabitation in China, which leads to a limited understanding of the phenomenon. Given the aforementioned differences between cohabitation in Western countries and China, it is uncertain if the existing theories and conclusions for cohabitation in Western countries apply to the context of China. There has been empirical evidence of characteristics of cohabitors in China that are different from the previous literature. For example, contrary to the findings in the majority of Western literature that cohabitors are less-educated, $\mathrm{Yu}$ and Xie (2015) reached the opposite conclusion that Chinese cohabitors are from the better-educated group. A deeper understanding of how education and cohabitation relate to each other will not only provide valuable insights into the nature of this rising 
phenomenon in China, but also contributes a case study on how demographic changes develop in a different institutional and cultural context.

By using longitudinal data from the China Family Panel Studies (2010-2016), a detailed study of the applicability of the existing Western theories in China is carried out in this paper. Specifically, this study will investigate the nature of the relationship between education and premarital cohabitation through examining whether the likelihood of premarital cohabitation differs among education groups and between genders. Moreover, this study will for the first time investigate how the association between education and premarital cohabitation changes over time across different marriage cohorts and whether the diffusion process has happened like what has been observed in Western countries.

\section{LITERATURE REVIEW}

This section will introduce the theoretical framework and empirical evidence of education and cohabitation in Western countries, followed by a discussion on the unique institutional context in China and recent changes in Chinese family formation in the post-reform era, as well as the current literature on cohabitation and education in China. Finally, hypotheses will be generated from the literature review.

\section{Theoretical Framework}

Thomson and Bernhardt (2010) suggested that the understanding of how education influences cohabitation structurally and ideologically is still limited. As a different form of an intimate relationship, cohabitation resembles marriage in many aspects, including co-residence and sexual activity. The role of cohabitation has traditionally been categorised as an alternative to marriage or as a transitional stage prior to marriage (Heuveline \& Timberlake, 2004). Thus, this section presents the main theories about the relationship between education and intimate 
union formation, which includes both marriage and cohabitation. This is in line with the previous literature on this topic (Ikamari, 2005; Thomson \& Bernhardt, 2010).

Broadly speaking, there are two approaches to examining the relationship between education and union formation. The first approach emphasises the mechanism, entailing the pathways through which education influences union formation. Two main theories belong to this approach, including economic theory and ideological theory. The second approach, represented by diffusion theory, focuses on the progress or development of the relationship at the societal level. The following section will explain these theories in more detail and argue that the diffusion theory provides a more relevant framework for this empirical study, i.e. understanding the evolving relationship between education and cohabitation in China.

According to the economic theory, education can influence the possibility and timing of union formation either negatively or positively. Negative economic theory suggests that education raises the opportunity cost of entering into marriage or cohabitation, thereby reducing the incentives for people to form unions. According to Becker's new home economics theory (1981), men and women trade with each other in the marriage market akin to firms to maximise their utilities. In the traditional society where the level of women's educational attainment and participation in the labour market was much lower than that of men, marriage formation benefited both parties, as men and women specialised in the labour market and family respectively. However, rising educational and labour market opportunities for women have made them more independent of men's economic support and increased the opportunity cost of entering into marriage, which made marriage less desirable. As a form of union, although cohabitation is less desired, the opportunity cost of entering into cohabitation is lower than that of marriage, as it is associated with lower commitments in comparison to marriage (Thornton et al., 1995). Therefore, cohabitation may become an alternative to marriage for dual-earner relationships. 
Positive economic theory, on the other hand, suggests that education has a positive effect on union formation by providing the necessary resources required for family functions. Education enables individuals to become economically independent and provides employment and income to support a thorough search for partners (Thomson \& Bernhardt, 2010). This is in line with Oppenheimer's $(1988,1997)$ job search theory - that a marriage search is similar to a job search, especially in terms of the match sought and the duration of the search. Although education may affect marriage timing by delaying the transition to a stable work role, in the long run, education and consequential improvements in the labour market and earnings could improve one's position in the partnership market, facilitate the capacity of finding a suitable residence, and secure resources for stable family life (Oppenheimer, 1988). In this case, cohabitation can be seen as a transitional stage for those who are less advantageous economically to accumulate resources before entering into marriage.

However, the application of these theories depends largely on the societal contexts, in particular, gender relations and the institutional environment supporting or restraining the family-work compatibility (Bernhardt, 1993; Thomson \& Bernhardt, 2010). For example, Thomson and Bernhardt (2010) pointed out that in places where social policies and cultural practices promote gender equality and the compatibility of work and family life, education tends to play a positive role in providing resources for people to enter into unions. However, in situations where gender role specialisation is high, the positive economic theory can still apply to men as education associates them with a higher earning potential that better fulfils the 'bread-winning' role. In contrast, the negative economic theory can be applied to women, who face a significant opportunity cost of forming unions and bearing children (Thomson \& Bernhardt, 2010). In such cases, cohabitation may be more popular among highly educated women. 
Ideological theory suggests that education changes the desirability of marriage or cohabitation via shaping the attitudes and values held by people. The process of education makes people more individualistic by exposing them to alternative ideas and preferences to their family origin. This rise in individualisation was widely recognised as a driving force of the second demographic transition (Lesthaeghe, 1983; Rindfuss \& VandenHeuvel, 1990). Education also produces values that place self-fulfilment above forms of collective life, e.g. family or marriage (Thomson \& Bernhardt, 2010), which undermines the values required for family formation. This effect is more obvious in traditional societies where women rely on marriage and childbearing to gain social status. In such context, when education liberates women from the expectations of early marriage and childbearing, it gives them new career opportunities and personal goals (Caldwell \& Caldwell, 1987; Ikamari, 2005), which makes marriage less desirable.

The application of ideological theory also depends on the societal environment. In societies where a higher degree of values is placed on individual autonomy and gender equality and when cohabitation is widely approved, education may have little influence on the desirability of cohabitation or marriage (Thomson \& Bernhardt, 2010). However, in societies where these ideas are not so common, education may have a significant influence, especially for women (Yu \& Xie, 2015).

In contrast with the aforementioned theories, the diffusion theory shifts the perspective from mechanism to societal-historical development. It points out that even within the same society, the application of the theories is heavily influenced by institutional and cultural changes. Therefore, the relationship between education and cohabitation is expected to follow a dynamic developmental process. In 2001, Kiernan introduced a diffusion thesis for understanding how the pattern of cohabitation evolves in different historical stages. By examining the extent and depth of changes of cohabitation in Western Europe, Kiernan 
(2001) describes a trajectory that cohabitation has taken, from being a deviant behaviour at the primitive stage, to functioning as either a prelude to marriage or a trial marriage in the second stage, to becoming more socially acceptable as an alternative to marriage in the third stage, and finally becoming indistinguishable from marriage in the last stage. Thus, the phenomenon of cohabitation can be seen as a gradual and incremental process from innovation to diffusion. During this process, the relationship between education and cohabitation changes accordingly. When cohabitation is still a deviant behaviour, ideational changes are important for distinguishing cohabitors from non-cohabitors. Thus, education is more likely to influence cohabitation choice by bringing about changes in values and attitudes. As cohabitation gains wider acceptance, education may impact cohabitation choice more from an economic perspective.

Chinese society has undergone dramatic changes in the last few decades after the economic reform was initiated. From its origins as a deviant behaviour, cohabitation has gradually gained increasing acceptance in society (Yu \& Xie, 2015). With the transition from a planned economy into a market economy and the expansion of education, the norms of gender role specialisation have also changed from a male-breadwinning/female-homemaking dichotomy to a dual-earners model. However, a resurgence of gender inequality in both family and labour market has been observed in recent years (Cao \& Hu, 2007). As societal environment changes and cohabitation progresses from being an innovative behaviour to increasingly common practice, it is reasonable to suggest that the relationship between education and cohabitation has also evolved. Thus, it is not adequate to understand this relationship from a static perspective, and the diffusion theory provides a better framework to understand how the economic and ideological theories worked in various stages of the postreform era. 


\section{Empirical Evidence}

The majority of Western literature has focused on the mechanism approach. An inverse relationship between cohabitation and education has been found consistently, meaning that better education is associated with a lower possibility of cohabitation and a higher likelihood of marrying directly. For example, using panel data of mothers and children drawn from the Detroit metropolitan area from 1961 to 1985, Thornton et al. (1995) found that people with little school accumulation cohabit at higher rates than those with greater accumulation. This suggests that people with lower school accumulation substitute cohabitation for marriage, at least for a period of time, while those with more accumulation are more likely to marry directly. Using a national sample survey of 13,017 respondents conducted in 1987-1988 in the United States, Bumpass et al. (1991) further confirmed that for all birth cohorts born from 1930 to 1960, cohabitation among young adults was the least amongst the college-educated people. The cohort comparison showed that the college-educated did experience an increase in cohabitation in the $1970 \mathrm{~s}$, but the growth rate was less than that for less-educated counterparts (i.e. those who did not complete high school). Thus, college graduates are not innovators in the dissemination of cohabitation but are imitators. This trend was further affirmed by Bumpass and $\mathrm{Lu}(2000)$ using a more recent national dataset in the United States, where they found that cohabitation rose among all education groups between 1987 and 1995, but the greatest relative increase occurred among high school graduates (44\%), and the least growth was among college graduates $(19 \%)$.

Therefore, research based on both local and national samples from 1961 to 1995 have consistently pointed to the inverse relationship between education and cohabitation, and this negative association has been strengthened in recent years. The standard explanation provided by these findings is the lack of financial resources for less-educated people. This is concurrent with the positive economic theory mentioned in the previous section, that 
education has a positive effect on union formation by providing necessary resources for mate search and for establishing a household. When faced with economic constraints, people may take cohabitation as a substitution for marriage in the early years of union, as cohabitation is associated with lower commitments as opposed to marriage (Thornton et al., 1995).

However, it is important to point out that the empirical evidence discussed above is predominantly from the United States. Research findings from other countries are not necessarily similar. For example, using data from the Swedish Young Adult Panel Study between 1999 and 2003, Thomson and Bernhardt (2010) concluded that the risk of cohabitation is not associated with prior educational attainment or ongoing enrolment. This is interesting, especially since earlier research in Sweden (Hoem, 1986) have found that cohabitation was pioneered by the working class rather than the college graduates using a sample of Swedish women born in 1936-1960.

These contradictory findings suggest that the relationship between education and cohabitation not only varies across countries, but also changes over time within one country as its institutional and cultural context changes. This supports the diffusion theory. When cohabitation rate was still low in Sweden, education had a negative effect on cohabitation. For the more recent cohort, almost all new unions start from cohabitation. The differential effect of education on cohabitors no longer exists in this family-friendly, gender-egalitarian welfare state (Thomson and Bernhardt, 2010). Since the majority of datasets used in the empirical research in the United States were collected before 1995, further research using more recent data might show varied outcomes to past studies.

The diffusion effect over time within a country has also been confirmed by Bhrolchain and Beaujouan (2013) using data from the British General Household Survey from 19792007. However, the direction of change is opposite to what has been found in Sweden. Specifically, cohabitation began among the best educated rather than the least educated 
women in the 1970s and 1980s. But over time, the lower educated overtook the higher educated group. The explanation is that the well-educated were the pioneers of value change who embraced nonconformist and anti-authoritarian attitudes and rejected traditional marriage. Thus, they were the 'innovators' of cohabitation in the early stage. This concurs with the ideological theory mentioned in the previous section and suggests that the trajectory of the relationship between education and cohabitation might be different, depending on the historical and cultural context where cohabitation emerged from.

Therefore, cohabitation is a dynamic process both in the individual life course and over time in society (Bhrolchain \& Beaujouan, 2013). Ultimately, it is an individual choice made in a specific institutional and cultural context. With the changes of social and cultural acceptability of cohabitation, and the changes of gender relations and demographic structure in the broader context, the relationship between education and cohabitation is expected to change accordingly (Manting, 1996; Smock, 2000; Bhrolchain \& Beaujouan, 2013).

\section{The Case of China}

In China, cohabitation was extremely rare both in the traditional Chinese society before 1949 and under the socialist regime between 1949 and 1978 (Zheng et al., 2011), but has gradually gained popularity in the recent decades. The proportion of couples cohabiting before marriage has grown from around $10 \%$ in the late 1970 s to nearly one third in the recent marriage cohort (Yu \& Xie, 2015). The growing popularity of cohabitation is interlinked with other changes in Chinese society in the post-reform era. This section will first introduce two dimensions of changing relationships: between the individual and the State, and between men and women. Thereafter, education expansion will be reviewed, and empirical findings on education and cohabitation in China will be addressed.

First, the increasing popularity of cohabitation is a result of the changing relationship between the individual and the State. Specifically, it is a process of the gradual withdrawal of 
the State from individuals' family decisions and the Chinese family transitioning from being a unit of the extended community into a self-reliant private institution based on voluntary contracts (Davis, 2014). Before the economic reform started, Chinese family life was under strong state control from 1949 to 1978. The primary purpose of marriage was no longer procreation to continue the family line like in the traditional Chinese society, but to serve the State, which has unprecedented power to shape family life through regulating marriage formation and dissolution (Palmer, 1995; Wolf, 1984). Attitude towards sex was extremely prohibitive and conservative during this period. Sex outside marriage, both premarital and extramarital, was regarded as highly immoral (Zheng et al., 2011). In such a context, cohabitation was socially unacceptable and was seen as immoral.

However, this view on cohabitation took a dramatic turn after the economic reform started in 1978. The most distinctive feature of this period is that the State withdrew from most aspects of family life (except for a few areas such as fertility) and started recognising the family as a private institution. Davis (2014) has summarised this change as a "triple turn", including "a turn towards marriage as a voluntary contract, a turn away from close surveillance of sexual relationships, and a turn away from protection of communal property." For instance, one of the most profound changes of the Revised Marriage Law of 2001 is to strengthen the protection of individual properties, especially prenuptial properties. In addition, notarised agreements between spouses are recognised as legally enforceable (Davis, 2014). These changes indicate that the idea of voluntary contract has been extended to intimate relationships. In this context, cohabitation has gained increasing acceptability. The interpretation of the Marriage Law by the Supreme Court of 2013 explains that cohabitation only comes into the court's purview in the case of a contested divorce or assigning compensation (Davis, 2014). This further confirmed that the State views cohabitation as a personal choice. 
The second changing relationship in the post-reform era is gender relations. From 1949 to 1978 , under the socialist regime, a rapid increase in the status of women was observed both within the family and in the labour market in China. The Communist Party promoted the ideology of gender equality in this period, with a dual purpose of liberating women from the oppression of traditional family, and making use of women as a vast reserve of labour power to contribute to building the socialist economy (Wolf, 1984). The Marriage Law of 1950 outlawed the long-practised arranged marriages and polygamy (Davis, 2014), and abolished the supremacy of men over women (Wolf, 1984). The rate of women's labour force participation increased by five times in the 1950s (Hare-Mustin, 1982) and reached nearly 90 percent at the eve of the economic reform (Hughes \& Maurer-Fazio, 2002).

However, after the economic reform started, gender inequality worsened. With the job allocation system abandoned, individuals face more competition in the job market as the education expansion grows. Meanwhile, employers have higher autonomy to make decisions on recruitment and wage allocation. As a result, the discrimination against women in the labour market has grown (Hughes \& Maurer-Fazio, 2002). For example, previous research (Khan, 1996) has found larger wage gaps between men and women in areas where market forces are more prevalent, such as eastern coastal provinces and the urban regions. A slower wage growth (Shu \& Bian, 2003) and a higher possibility of being laid off (Cao \& Hu, 2007) have also been found among women, with married women experiencing greater discrimination than single women (Hughes \& Maurer-Fazio, 2002).

Therefore, in contrast to Western societies where a consistently decreasing gender inequality has been observed (Inglehart \& Norris, 2003), the inequality of gender relations in China has experienced a U-shape turn. Gender inequality has decreased under the socialist regime, but in recent years, there has been a resurgence of gender inequality in both the labour market and family life in China (Fincher, 2016; Mu \& Xie, 2014). As mentioned in the 
previous section, how education and cohabitation relate to each other depends largely on the social context, especially gender role specialisation and gender relations. Thus, it is reasonable to suggest that the relationship between education and cohabitation might be of a different nature in China from that in Western developed countries.

Alongside the changing relationships between the individual and the State, and between men and women, China has undergone a rapid education expansion in the post-reform era. Before the economic reform, most of the educational resources and employment opportunities were monopolised by the State through a centralised planning system (Wu \& Zheng, 2008). Higher education was almost exclusively restricted to very few elites. Since 1978, a nationwide educational reform was started (Deng \& Treiman, 1997; Han, 2000) to boost economic development. These educational policies include the implementation of compulsory basic education and expansion of higher education (Han, 2000), which caused a large expansion of education on all levels.

The implementation of the nine-year compulsory education policy was started in 1985 to eliminate illiteracy and in turn reduce poverty. Rural people and women benefited the most from this system by gaining equal access to primary and junior-high school education. Consequently, the gender gap in primary education also narrowed considerably and nearly disappeared from 2002 onwards (Zhang \& Minxia, 2006). Meanwhile, higher education had been transformed from an elite system to a mass education system through privatisation and decentralisation (Wu \& Zheng, 2008). From 1978 to 1998, the number of new college student enrolment almost tripled from 0.4 million to 1.08 million, and the total number of college students quadrupled from 0.86 million to 3.41 million (Li \& Zhang, 2010). By 2006, the number of students enrolled in higher education institutions had risen to 25 million, with the gross enrolment rate reaching $22 \%$ (Wu \& Zheng, 2008). Similar to primary education, the gender gap in higher education has also declined and even reversed (Yeung, 2013). By 2009, 
the female college enrolment had already surpassed that of men.

As China transitioned from a planned economy to a market economy, socio-economic status has increasingly been determined by education rather than political capital (Zhao \& Zhou, 2002; Zhang et al., 2005). The earning potential tends to increase with more education. For example, Zhao and Zhou (2002) found that in the late 1990s, college graduates earn 50\% more than high school graduates, and high school graduates earn $20 \%$ more than those with less than six years of schooling. However, there is a gender gap in terms of the return of education, as a result of gender discrimination in the labour market.

Research on the association between educational attainment and cohabitation on the individual level in China is limited due to the lack of publicly available survey data (Jones, 2007). Since 2010, the China Family Panel Studies survey data have become available to researchers, and this provides a useful resource for research on this topic. Xie (2013) and $\mathrm{Yu}$ and Xie (2015) found that better education is positively associated with cohabitation (i.e. education increases the likelihood of cohabitation for individuals). Yu and Xie (2015) used the ideological theory to explain the results, suggesting that this difference is because better educated people in China are more likely to adopt Western liberal values, such as a more tolerant view towards sexuality and a more egalitarian outlook of gender relations. They also suggested that cohabitation in China is still a marginal phenomenon pioneered by the welleducated group, but this might change in the future to resemble the trend currently observed in Western developed countries. Thus, they suggested that when cohabitation is more widely accepted, lower-income and less-educated individuals will gradually overtake the better educated group to cohabit.

While the findings of $\mathrm{Yu}$ and Xie (2015) provided valuable insights into the determinants of cohabitation in China, how the association between education and cohabitation over time has not been investigated thus whether the diffusion process has 
happened remains unknown. As mentioned previously, China has experienced dramatic societal changes over the past few decades. The family choices of each marriage cohort were influenced by the distinct education policies and legal frameworks of marriage of the time. Therefore, an investigation of the variation across different marriage cohorts will help understand how the relationship between education and cohabitation evolves over time.

Furthermore, it is too simplistic to suggest that cohabitation in China will resemble the trend of Western developed countries, as proposed by Yu and Xie (2015). While the popularity of cohabitation in China and Western countries both reflects a fundamental ideational change in the society such as growing individualisation, the process in China is the changing relationship between the individual and the State, instead of a categorical shift in the individual-society relationship as happened in Western countries (Yan, 2010). Although the State is increasingly privatising intimate relationships, the whole process is still primarily State-led, and the strong influence of State-induced policies cannot be neglected. While sexuality is increasingly becoming privatised, fertility decisions such as the occurrence and the number of children are still strongly regulated by the government through the birth permit, household registration and family planning policies.

Therefore, the fundamental differences between the institutional contexts mean that the development of cohabitation practice in China might follow a different trajectory from that of Western countries. A better understanding of the time dependency of the relationship between education and cohabitation will not only provide key insights into the nature of this new type of relationship in China, but also serve as a case study of how demographical changes develop differently in an institutional context with strong state control. Thus, this study will explore the association between education and premarital cohabitation and how it changes over time by testing the following hypotheses.

As mentioned in the previous section, the application of economic theory and 
ideological theory depends on the societal context. Since the Chinese society has historically been characterised as collective rather than individualistic and a resurgence of gender inequality has been observed in the post-reform era, education is likely to impose its influence on individuals through introducing more individualistic and egalitarian ideas. Therefore, this study hypothesises that better education is associated with a higher likelihood of premarital cohabitation. This is also consistent with Yu and Xie (2015)'s findings.

Hypothesis 1: There exists a positive association between education and premarital cohabitation among married individuals in China.

The diffusion theory suggests that the association between education and premarital cohabitation changes within a society over time. In particular, when cohabitation is a marginal phenomenon, education is more likely to influence the choice of individuals by introducing individualistic and non-traditional family values. But as cohabitation becomes more popular, the ideological effect decreases, and education exerts its impact more from an economic perspective. Since education provides better job opportunities and earning potentials, better educated people might marry directly while cohabitation becomes a transitional stage for less educated individuals to accumulate more resources before marriage. As cohabitation has grown from being a rare phenomenon to a common choice in postreform China, this study hypothesises that the positive association between education and premarital cohabitation decreases over time.

Hypothesis 2: The positive association between education and premarital cohabitation decreases across marriage cohorts, and even reverses in the most recent marriage cohort.

Past research suggests that the empowerment effect of education is stronger for women than men, meaning that better educated women hold more gender egalitarian views than men with similar education levels (Shu, 2004). As a result, the ideological effect of education 
might be stronger for women than men. Therefore, this study hypothesises that the positive association between education and cohabitation is more evident among women.

Hypothesis 3: The positive association between education and premarital cohabitation is more evident for women than men.

\section{METHOD}

\section{Data}

This study uses pooled data consisting of detailed education and cohabitation histories from four waves of the China Family Panel Studies (CFPS) between 2010 and 2016. Started in 2010 by the Institute of Social Science Survey of Peking University, the CFPS is a nationally representative longitudinal survey conducted to collect data from Chinese families and individuals on economic activities, education outcomes, family dynamics and relationships, migration, and health (Xie \& Hu, 2014). Using stratified multistage sampling methods (county-village-household), 14,798 families (consisting of 24,610 adults and 8,990 children) were interviewed for the 2010 baseline survey with an approximately $79 \%$ response rate. These individuals comprise core members of the CFPS and have been subsequently followed up on a yearly basis. Every year, new family members co-residing with the original respondents were added to the sample as new core members. The sample of CFPS 2016 consists of 36,892 adults and 8,427 children. $^{2}$

The CFPS data contains the retrospective information of premarital cohabitation history and is highly suited for addressing the research questions of this study. However, the lack of available data on currently cohabiting couples means that comparison cannot be made

\footnotetext{
${ }^{2}$ The sampling methodology and the assessment of the quality of the data was discussed extensively in the introduction to the CFPS (Xie \& Hu, 2014).
} 
between currently cohabiting individuals and married individuals. Since not every

cohabitation will lead to marriage, including only the successful cases provides an incomplete picture of the relationship between education and cohabitation. Nevertheless, since the majority of cohabitating relationships lead to marriage and multiple cohabitation experiences are rare in China (Xie, 2013), the examination of the relationship between education and premarital cohabitation among married individuals will still provide valuable insights into the bigger question of the relationship between education and cohabitation in general. Moreover, since premarital cohabitation experience was recalled by both spouses separately, it offers an opportunity to cross check their answers. This study treated both spouses as having had premarital cohabitation experience if at least one of them reported positively. $0.3 \%$ of all couples had non-matching information, where one spouse reported having premarital cohabitation history while the other reported having none. For such cases, both spouses from these couples were treated as having had premarital cohabitation experience.

This study only focuses on the cohabitation experience before first marriages. Previous research shows that the cohabitation rate in China has two distinct peaks corresponding to young adults and older people respectively, where the latter are typically widowers living together without marriage to avoid inheritance complications ( $\mathrm{Fu}, 2010)$. To avoid confusion with the interpretation of results, the sample in this study is limited to only the cohabitation experience before first marriages. Moreover, the scope of this study is cohabitation and marriages in the post-reform era (after 1978); therefore, only marriages formed during the period after the economic reform started were kept in the sample. To better control for the legal environment, marriages formed before 1980 were dropped because the Marriage Law of 1980 brought about significant changes around legislations of marriage. In addition, individuals married after 35 years old were excluded from this study to best capture the cohabitation and marriage choices among young adults. 
Data collected from four waves (2010, 2012, 2014, and 2016) from CFPS were pooled together to increase the sample size. As a result, a total of 48,705 cases were included in the analysis, consisting of 23,692 females and 25,013 males. To take account of the multiple observations of the same individuals from different waves, robust standard errors were used. Moreover, cross-sectional weights were used for all analyses to increase the representativeness of the population.

\section{Measures}

The dependent variable for the logistic regression is the cohabitation experience before marriage. Cohabitation is defined in this study as living with a partner in an intimate relationship without being married to each other. During the surveys, all married individuals were asked a series of questions regarding their marital history and whether they had ever cohabited with their current spouse before getting married. The response to this question constitutes the individual's cohabitation experience. A binary variable was created with 1 indicating having cohabited before marriage and 0 meaning no such experience.

A key independent variable for the regression is the highest level of educational attainment of the individual, as reported at the time of the survey. The level of education at the time of the survey is assumed to be the same as the level of education at the time of the first marriage, because the level of education of individuals in China does not tend to change after marriage (Qian \& Qian, 2014). For this study, a categorical variable was used to capture five different levels of educational attainment: illiterate, primary school, junior-high school, senior-high school, and college education and above. Rather than illiterate people, individuals with primary school education were used as the reference group in logistic regression models, so that the results could better reflect the nuanced differences amongst different educational levels.

Other demographic and economic variables that may be associated with both education 
and cohabitation outcome were included to control for confounding factors. Previous research has shown that family socio-economic position influences both union formation and educational attainment (Axinn \& Thornton, 1992). Thus, several control variables relating to family origin were included, namely father's educational attainment, father's Chinese Communist Party (CCP) membership, ethnicity, hukou status at 12 years old and geographical regions.

Father's highest level of education is preferred over the mother's, as it is a better predictor for the economic status of the family considering the gender discrimination towards women in the labour market (Hughes \& Maurer-Fazio, 2002). In this study, father's education was divided into three levels: illiterate, primary school, and secondary school and above, because not many people have accomplished education beyond secondary school. Furthermore, social and political capital has been known to be a major predictor for the socio-economic status of a family under the socialist regime (Hauser \& Xie, 2005). This is measured by a dichotomous variable indicating whether the father is a CCP member or not. Furthermore, there is an unequal distribution of economic and educational resources in China, which resulted in significant inequality amongst ethnic minority groups, rural people, and certain geographical areas in China (Xie, 2016; Bian, 2002). Thus, the control variables included dichotomous measures for ethnicity (Han versus ethnic minority), for hukou status at 12 years old (rural hukou versus urban hukou), and a continuous variable measuring GDP per capita of each individual's birth province. Hukou status at 12 years old rather than current hukou status was used because it better reflects an individual's socio-economic origin and the educational resources available growing up (Ma \& Rizzi, 2017).

Besides the variables relating to the family origin, age was also controlled because education, cohabitation, and marriage change dramatically over the young adult years (Thornton, 1988). Lastly, the survey year was controlled to minimise the bias of the findings 
due to sampling errors. As the focus of this research is centred on the relationship between education and cohabitation, the results of the control variables will not be discussed extensively.

\section{Analytical Plan}

Logistic regressions were conducted to examine the association between education and the likelihood of premarital cohabitation. Two different models were conducted. While the first model focused on the raw relationship between educational attainment and premarital cohabitation experience, the second model examined this association in more detail controlling for potential confounding factors.

To examine how the association between education and cohabitation changes over time, three different marriage cohorts were isolated as follows: 1981-1992, 1993-2001, 20022016. The reasons for dividing marriage cohorts in this way are because both 1992 and 2001 mark important milestones of both the economic reform and legislations around cohabitation. The reform was expanded by the Chinese government in 1992 and privatisation began to accelerate as a result (Naughton, 2008), while in 2001, cohabitation was legally recognised in the Chinese Marriage Law for the first time (Yu \& Xie, 2015). Thus, dividing cohorts in this way can to a large extent control for the institutional environment in which individuals make their family choices. Furthermore, logistic regressions were carried out separately for men and women in each marriage cohort, as previous studies (Yu \& Xie, 2015) have observed gender differences in the prevalence and determinants of cohabitation. 


\section{RESULTS}

\section{Descriptive Results}

This study aims to investigate the association between education and premarital cohabitation across different marriage cohorts in post-reform China. Before looking at the regression findings, descriptive results are first presented.

Figure 1. The Rise of the Age of First Marriage and Years of Education for Married Males 1949-2016

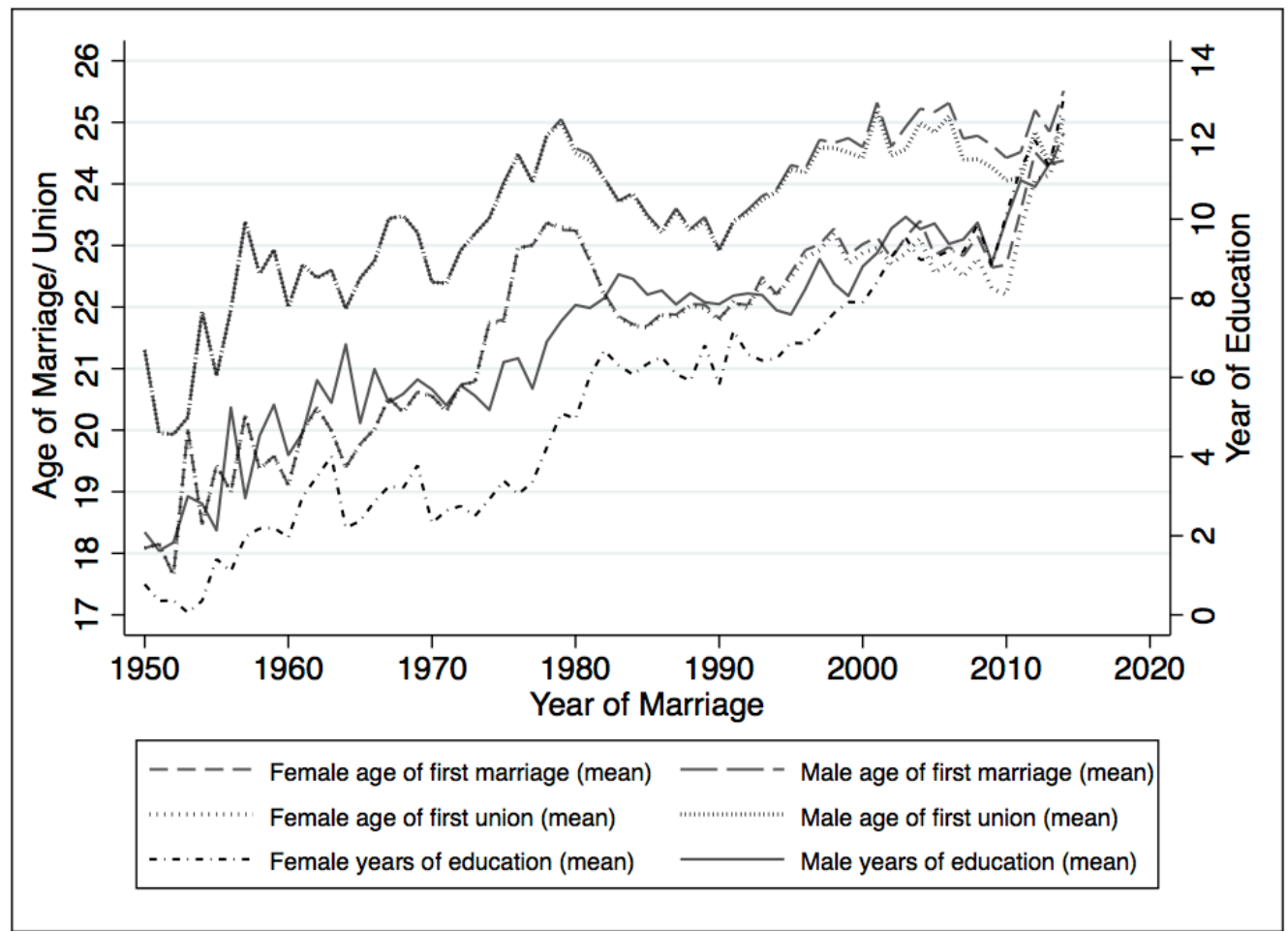

Source: Pooled Data from CFPS 2010-2016.

Notes: Results are weighted using cross-sectional weight.

Figures 1 shows the increase in the years of education and the age of first marriage from 1949 to 2016 for married men and married women in the sample. The average years of education increased by 10 and 13 years for men and women respectively, while the age of first marriage increased by about 5.5 years and 7 years for men and women respectively. Thus, the age of first marriage seems to rise in tandem with the number of years of education.

Overall, there is a general increase in the age of marriage for both men and women over the past few decades. For example, the mean age of first marriage for women has 
increased from 17.8 years old in the 1950 s to 24.8 years old in 2016 . For men, the increase has been from 20 to 25.5 years old over the same period. The rise in the age of first marriage has been consistent, except for a sharp rise in the late 1970s followed by a drop in the early 1980s. This may be due to a government policy that promoted late marriages in the 1970s and encouraged people to get married in their late twenties. However, the 1980 Marriage Law then lowered the legal marriage age to 20 years for women and 22 years old for men, which gave people the freedom to marry at a younger age again, thus setting up the drop in the age of first marriage in the early 1980s.

By comparing the age of first union (i.e. cohabitation) against the age of first marriage, some insights into the cohabitation trend can be identified. First, it is evident from Figures 1 that the prevalence of cohabitation amongst married couples increased substantially after the early 1990s for both women and men, as shown by the increasing gap between the two age-related curves. Second, the figure shows that the average duration of cohabitation tends to be short, delaying marriage by less than 1 year. 
Figure 2. Percentage of Premarital Cohabitation Across Educational Attainment and Marriage Cohorts for Married Males

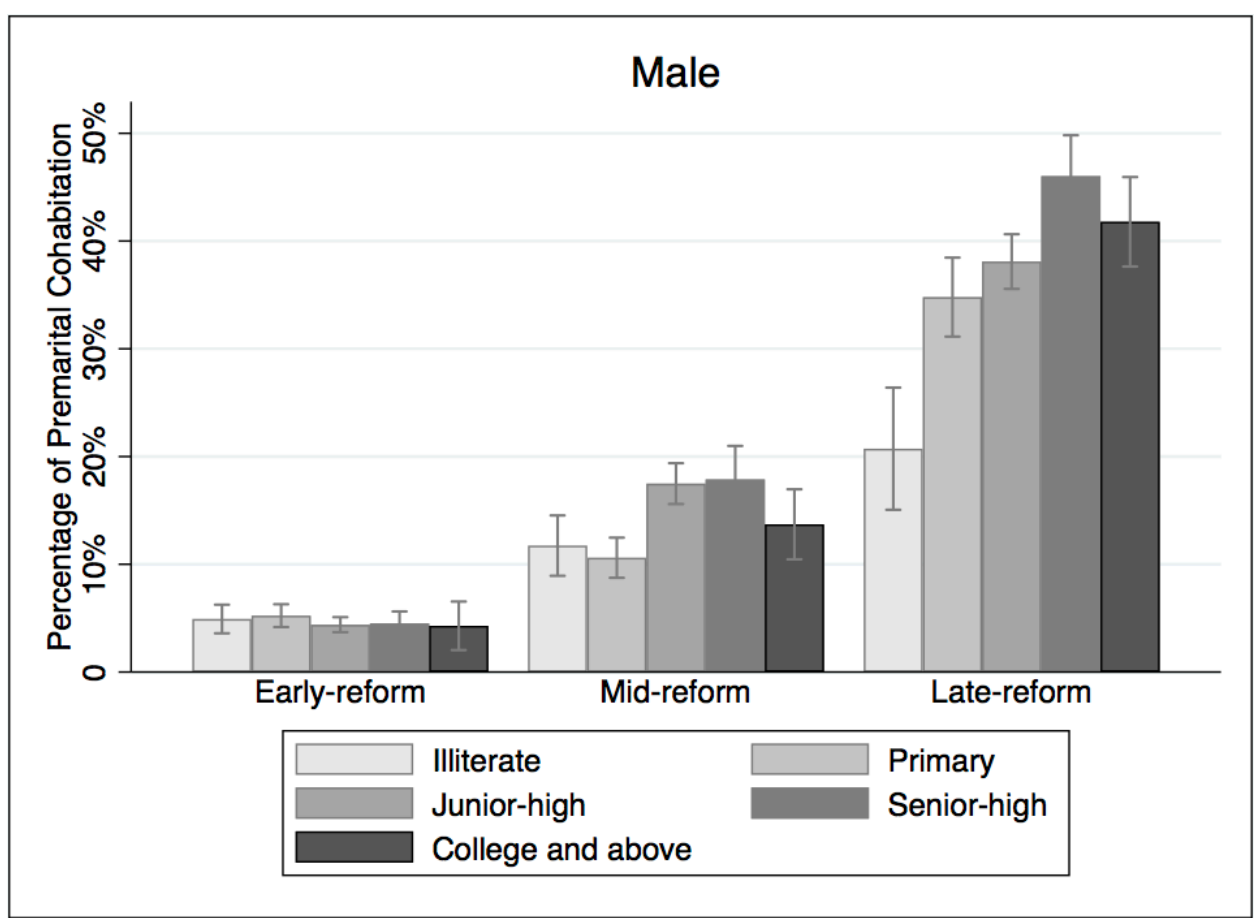

Source: Pooled Data from CFPS 2010-2016.

Notes: Results are weighted using cross-sectional weight and presented with $95 \%$ confidence intervals.

Figure 3. Percentage of Premarital Cohabitation Across Educational Attainment and Marriage Cohorts for Married Females

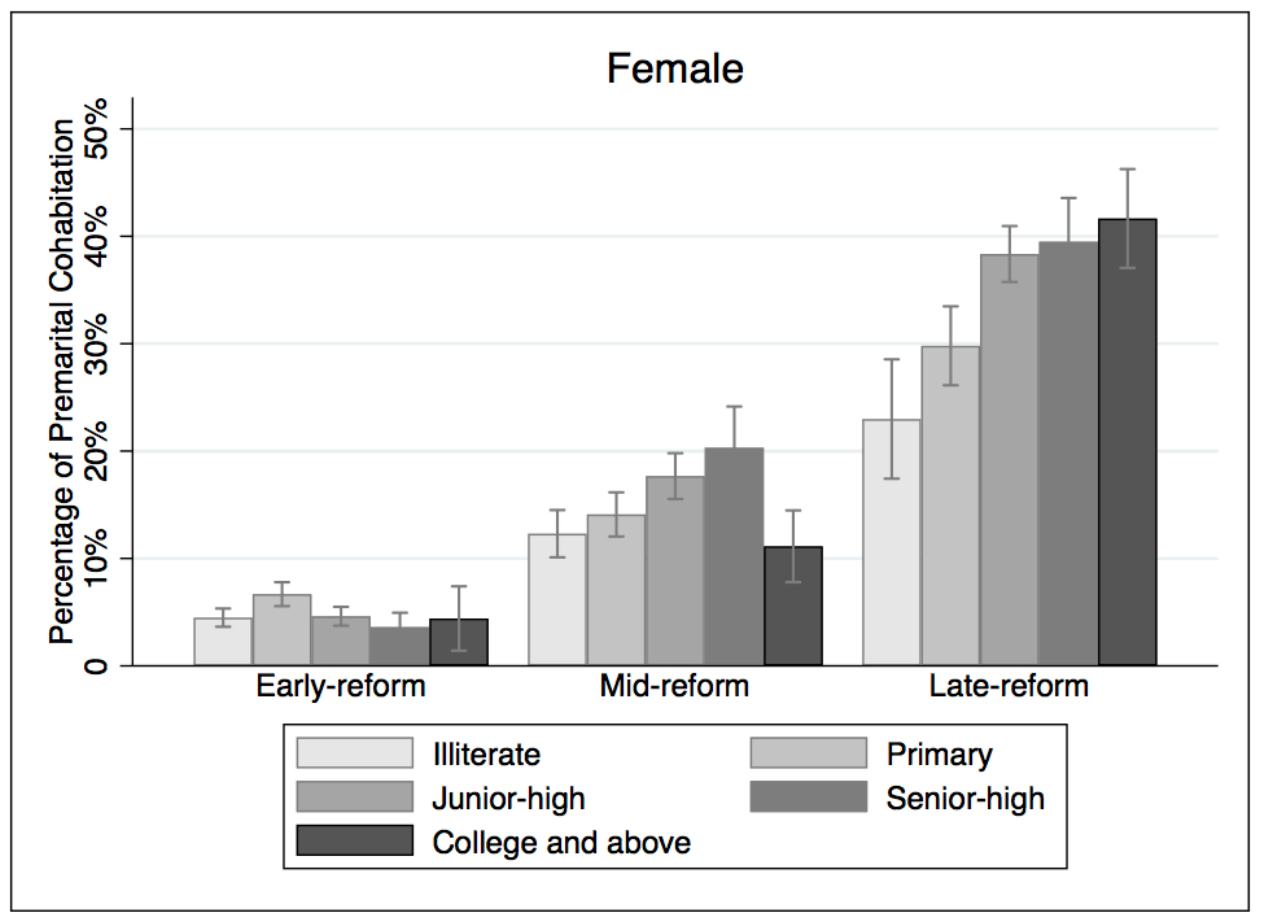

Source: Pooled Data from CFPS 2010-2016.

Notes: Results are weighted using cross-sectional weight and presented with $95 \%$ confidence intervals. 
To investigate the relationship between education and cohabitation in China, the cohabitation rate was calculated for different education groups in each marriage cohort. The results are shown in Figures 2 and 3 for men and women, respectively. In general, both figures show a substantial increase in cohabitation for both men and women. In the earlyreform era, cohabitation was a relatively rare phenomenon, with less than $10 \%$ of the people choosing to cohabit before marriage. In the last two decades, this number tripled and nearly one-third of men and women cohabited before their first marriage.

The rate of cohabitation has increased significantly across all education levels in the post-reform period. In the early-reform cohort (1981-1992), the rate of cohabitation was similar for all education levels, and no particular level of education stood out, except for illiterate and primary school educated females. However, the differentiating pattern of education and cohabitation becomes apparent in the mid-reform era (1993-2001). Among all education levels, the most significant positive effect comes from secondary school for both genders. Both junior-high and senior-high school educated males have significantly $7 \%$ higher cohabitation rate than primary school graduates, and the difference between seniorhigh school and primary school is $6 \%$ for females. One surprising finding is that college education is not associated with the highest cohabitation occurrence. Instead, it has a decreasing impact compared to senior-high school education, especially for females. This is different from Hypothesis 1, which posits that education is consistently positively associated with the cohabitation likelihood.

During the late-reform era between 2002 and 2016, the cohabitation rate continues to increase. For males, primary school education has replaced junior-high school to have the most significant positive association with a $35 \%$ cohabitation rate, almost doubling the rate of illiterate males. Senior-high school education significantly increases the cohabitation rate by about $8 \%$ compared to the previous education level, and it also has the highest cohabitation 
rate of $46 \%$ among all education groups. For females, similar to the former cohort, the most significant positive effect comes from junior-high school, where the cohabitation rate is $9 \%$ more than the previous education level. A key difference is that while college education increases the cohabitation rate for females, it has the opposite effect for males. It suggests that the positive association between education and premarital cohabitation is stronger for women than men, although the level of significance needs to be further tested.

The above results show that the relationship between education and cohabitation differs between men and women, and it changes with time across different marriage cohorts, although the direction is opposite to what Hypothesis 2 suggests. Instead of education having the most positive association with cohabitation in the early cohorts and then decreasing over time (as observed in Western countries), female cohabitors seem to be more and more positively selected over time. This is less obvious for men, where the positive association of education and cohabitation is strongest amongst the senior-high school educated group in the most recent cohort. This seems to support Hypothesis 3, which assumes that the positive association between education and cohabitation is more evident for women than men. However, the rate of cohabitation amongst the college educated males has risen fast and has overtaken the junior-high educated group to become the second largest pool of cohabitors in the most recent cohort. Thus, college educated males may be the largest group of cohabitors in the future, which would imply that there is a delayed effect for best-educated men compared to women. 
Table 1. Explanatory Variables by Cohabitation and Marriage Cohorts for Males

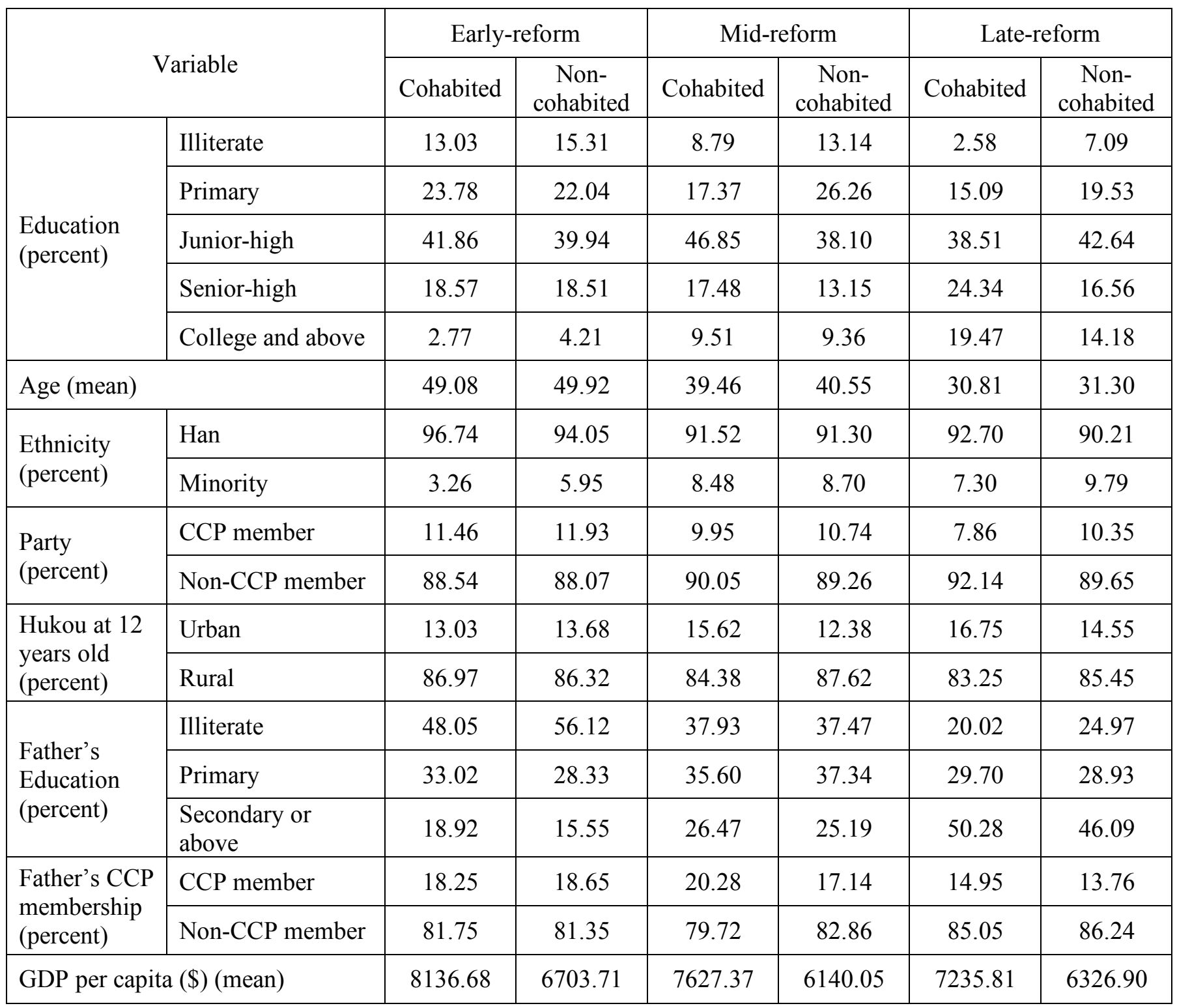


Table 2. Explanatory Variables by Cohabitation and Marriage Cohorts for Females

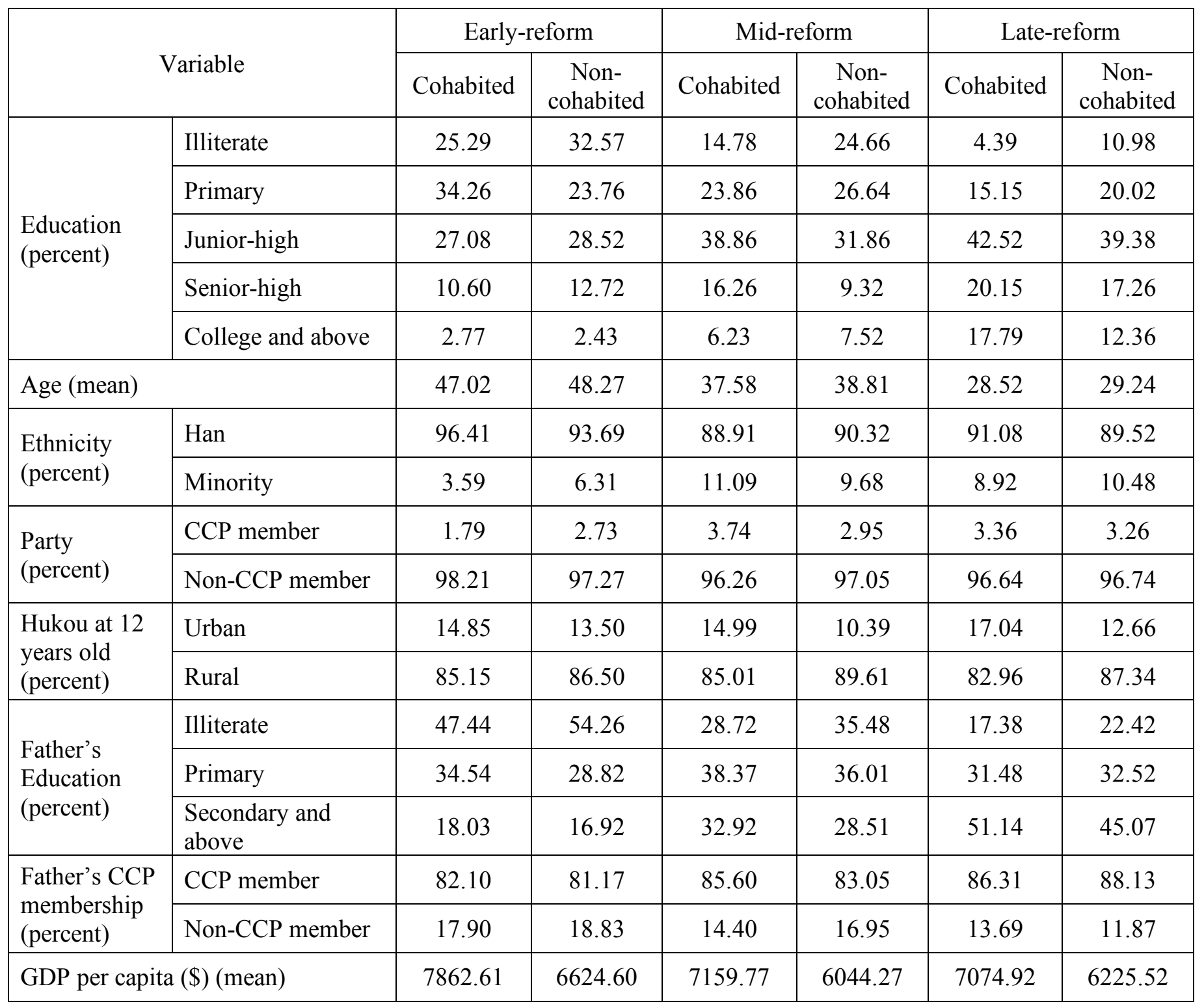

Table 1 and 2 show the explanatory variables by premarital cohabitation experience and marriage cohorts for both males and females. For both genders, individuals with premarital cohabitation experience are becoming increasingly better educated over time. In the early-reform marriage cohort, the majority of cohabited males (78.67\%) have education up to junior-high school, and this figure for cohabited females is even higher being $86.63 \%$. 
However, this is completely opposite by the time of late-reform cohort, with more than $80 \%$ of cohabited males and females having at least junior-high school education. The percentage of college-educated cohabitors increased dramatically, from only $2.77 \%$ for both genders in the early-reform cohort to $19.47 \%$ for males and $17.79 \%$ for females in the late-reform cohort, nearly seven times higher compared to that in the early-reform cohort.

In terms of other explanatory variables, cohabited individuals are younger, less likely to come from minority groups, more likely to have urban Hukou and come from families with higher socio-economic status (with fathers having better education and being CCP members). The only difference is that cohabited males are less likely to be CCP members, while this is not consistent for females. In China, CCP has stricter control of its member's behaviours; this difference shows that political factors are more influential on males than females in China. The relationship between education and premarital cohabitation needs to be further examined when these confounding factors are controlled for.

\section{Logistic Regression}

To test the association while controlling for other confounding variables, logistic regressions were carried out to examine the association between educational attainment and premarital cohabitation, and whether it has changed across marriage cohorts. 
Table 3. Odds Ratios for the Association of Educational Attainment and Premarital Cohabitation for Married Males by Marriage Cohorts in Post-reform China

\begin{tabular}{|c|c|c|c|c|c|c|}
\hline & \multicolumn{2}{|c|}{$\begin{array}{c}\text { Early-reform } \\
(1981-1992)\end{array}$} & \multicolumn{2}{|c|}{$\begin{array}{l}\text { Mid-reform } \\
(1993-2001)\end{array}$} & \multicolumn{2}{|c|}{$\begin{array}{l}\text { Late-reform } \\
(2002-2016) \\
\end{array}$} \\
\hline & Model 1 & Model 2 & Model 1 & Model 2 & Model 1 & Model 2 \\
\hline & Education & $\begin{array}{l}\text { Education+ } \\
\text { Confounding } \\
\text { factors }\end{array}$ & Education & $\begin{array}{l}\text { Education+ } \\
\text { Confounding } \\
\text { factors }\end{array}$ & Education & $\begin{array}{l}\text { Education+ } \\
\text { Confounding } \\
\text { factors }\end{array}$ \\
\hline \multicolumn{7}{|c|}{ Educational attainment (ref. primary school) } \\
\hline Illiterate & $\begin{array}{l}0.864 \\
(0.235)\end{array}$ & $\begin{array}{l}1.028 \\
(0.284)\end{array}$ & $\begin{array}{l}1.027 \\
(0.278)\end{array}$ & $\begin{array}{l}1.100 \\
(0.301)\end{array}$ & $\begin{array}{l}0.418^{* *} \\
(0.136)\end{array}$ & $\begin{array}{l}0.465^{*} \\
(0.155)\end{array}$ \\
\hline Junior-high & $\begin{array}{l}0.804 \\
(0.180)\end{array}$ & $\begin{array}{l}0.773 \\
(0.175)\end{array}$ & $\begin{array}{l}1.829^{* *} \\
(0.344)\end{array}$ & $\begin{array}{l}1.795^{* *} \\
(0.344)\end{array}$ & $\begin{array}{l}1.153 \\
(0.175)\end{array}$ & $\begin{array}{l}1.122 \\
(0.175)\end{array}$ \\
\hline Senior-high & $\begin{array}{l}0.988 \\
(0.285)\end{array}$ & $\begin{array}{l}1.010 \\
(0.283)\end{array}$ & $\begin{array}{l}1.540 \\
(0.373)\end{array}$ & $\begin{array}{l}1.693 * \\
(0.435)\end{array}$ & $\begin{array}{l}1.762^{* *} \\
(0.317)\end{array}$ & $\begin{array}{l}1.808^{* *} \\
(0.345)\end{array}$ \\
\hline College & $\begin{array}{l}0.789 \\
(0.344)\end{array}$ & $\begin{array}{l}0.782 \\
(0.361)\end{array}$ & $\begin{array}{l}1.282 \\
(0.367)\end{array}$ & $\begin{array}{l}1.425 \\
(0.458)\end{array}$ & $\begin{array}{l}1.412 \\
(0.277)\end{array}$ & $\begin{array}{l}1.553^{*} \\
(0.337)\end{array}$ \\
\hline \multicolumn{7}{|c|}{ Father's education (ref. illiterate) } \\
\hline \multicolumn{2}{|l|}{ Primary } & $\begin{array}{l}1.372 \\
(0.310)\end{array}$ & & $\begin{array}{l}0.812 \\
(0.146)\end{array}$ & & $\begin{array}{l}1.184 \\
(0.190)\end{array}$ \\
\hline \multicolumn{2}{|l|}{$\begin{array}{l}\text { Secondary and } \\
\text { above }\end{array}$} & $\begin{array}{l}1.270 \\
(0.361)\end{array}$ & & $\begin{array}{l}0.713 \\
(0.141)\end{array}$ & & $\begin{array}{l}0.999 \\
(0.159)\end{array}$ \\
\hline \multicolumn{7}{|c|}{ Father's CCP membership (ref. non-member) } \\
\hline \multicolumn{2}{|l|}{ CCP member } & $\begin{array}{l}0.973 \\
(0.265)\end{array}$ & & $\begin{array}{l}1.283 \\
(0.283)\end{array}$ & & $\begin{array}{l}0.831 \\
(0.165)\end{array}$ \\
\hline Ethnicity & & $\begin{array}{l}1.240 \\
(0.546)\end{array}$ & & $\begin{array}{l}0.915 \\
(0.280)\end{array}$ & & $\begin{array}{l}1.125 \\
(0.291)\end{array}$ \\
\hline \multicolumn{7}{|c|}{ Hukou status at 12 years old (ref. rural hukou) } \\
\hline & & $\begin{array}{l}0.957 \\
(0.312)\end{array}$ & & $\begin{array}{l}0.855 \\
(0.225)\end{array}$ & & $\begin{array}{l}0.787 \\
(0.139)\end{array}$ \\
\hline \multicolumn{7}{|l|}{ Provincial } \\
\hline GDP & & $\begin{array}{l}2.000 \\
(0.736)\end{array}$ & & $\begin{array}{l}2.697 * * * \\
(0.799)\end{array}$ & & $\begin{array}{l}1.517 \\
(0.359)\end{array}$ \\
\hline Age & & $\begin{array}{l}0.953^{*} \\
(0.020)\end{array}$ & & $\begin{array}{l}0.913 * * * \\
(0.021)\end{array}$ & & $\begin{array}{l}0.971 \\
(0.015)\end{array}$ \\
\hline \multicolumn{7}{|c|}{ Panel wave (ref. wave 2010) } \\
\hline Wave 2012 & & $\begin{array}{l}1.083 \\
(0.119)\end{array}$ & & $\begin{array}{l}1.023 \\
(0.102)\end{array}$ & & $\begin{array}{l}0.970 \\
(0.079)\end{array}$ \\
\hline Wave 2014 & & $\begin{array}{l}1.044 \\
(0.169)\end{array}$ & & $\begin{array}{l}0.984 \\
(0.153)\end{array}$ & & $\begin{array}{l}0.947 \\
(0.111)\end{array}$ \\
\hline Wave 2016 & & $\begin{array}{l}1.008 \\
(0.192)\end{array}$ & & $\begin{array}{l}1.126 \\
(0.208)\end{array}$ & & $\begin{array}{l}0.927 \\
(0.128)\end{array}$ \\
\hline Constant & $\begin{array}{l}0.061 * * * \\
(0.011)\end{array}$ & $\begin{array}{l}0.275 \\
(0.292)\end{array}$ & $\begin{array}{l}0.119 * * * \\
(0.019)\end{array}$ & $\begin{array}{l}2.822 \\
(2.418)\end{array}$ & $\begin{array}{l}0.478 * * * \\
(0.063)\end{array}$ & $\begin{array}{l}0.800 \\
(0.384)\end{array}$ \\
\hline Observations & 12248 & 12248 & 6886 & 6886 & 5879 & 5879 \\
\hline
\end{tabular}

Exponentiated coefficients; Robust standard errors in parentheses; ref. $=$ reference

$* \mathrm{p}<0.05 * * \mathrm{p}<0.01 * * * \mathrm{p}<0.001$

Source: Pooled Data from CFPS 2010-2016. Notes: Results are weighted using cross-sectional weight. 
Table 4. Odds Ratios for the Association of Educational Attainment and Premarital Cohabitation for Married Females by Marriage Cohorts in Post-reform China

\begin{tabular}{|c|c|c|c|c|c|c|}
\hline & \multicolumn{2}{|c|}{$\begin{array}{c}\text { Early-reform } \\
(1981-1992)\end{array}$} & \multicolumn{2}{|c|}{$\begin{array}{l}\text { Mid-reform } \\
(1993-2001)\end{array}$} & \multicolumn{2}{|c|}{$\begin{array}{l}\text { Late-reform } \\
(2002-2016)\end{array}$} \\
\hline & Model 1 & Model 2 & Model 1 & Model 2 & Model 1 & Model 2 \\
\hline & Education & $\begin{array}{l}\text { Education+ } \\
\text { Confounding } \\
\text { factors }\end{array}$ & Education & $\begin{array}{l}\text { Education+ } \\
\text { Confounding } \\
\text { factors }\end{array}$ & Education & $\begin{array}{l}\text { Education+ } \\
\text { Confounding } \\
\text { factors }\end{array}$ \\
\hline \multicolumn{7}{|c|}{ Educational attainment (ref. primary school) } \\
\hline Illiterate & $\begin{array}{l}0.754 \\
(0.156)\end{array}$ & $\begin{array}{l}0.876 \\
(0.182)\end{array}$ & $\begin{array}{l}0.916 \\
(0.198)\end{array}$ & $\begin{array}{l}0.996 \\
(0.219)\end{array}$ & $\begin{array}{l}0.631 \\
(0.170)\end{array}$ & $\begin{array}{l}0.588 \\
(0.178)\end{array}$ \\
\hline Junior-high & $\begin{array}{l}0.651 \\
(0.149)\end{array}$ & $\begin{array}{l}0.656 \\
(0.157)\end{array}$ & $\begin{array}{l}1.239 \\
(0.228)\end{array}$ & $\begin{array}{l}1.161 \\
(0.218)\end{array}$ & $\begin{array}{l}1.489^{*} \\
(0.240)\end{array}$ & $\begin{array}{l}1.513^{*} \\
(0.250)\end{array}$ \\
\hline Senior-high & $\begin{array}{l}0.688 \\
(0.230)\end{array}$ & $\begin{array}{l}0.686 \\
(0.215)\end{array}$ & $\begin{array}{l}1.678^{*} \\
(0.404)\end{array}$ & $\begin{array}{l}1.652 \\
(0.440)\end{array}$ & $\begin{array}{l}1.573^{*} \\
(0.312)\end{array}$ & $\begin{array}{l}1.635^{*} \\
(0.349)\end{array}$ \\
\hline College & $\begin{array}{l}0.910 \\
(0.425)\end{array}$ & $\begin{array}{l}0.790 \\
(0.398)\end{array}$ & $\begin{array}{l}0.730 \\
(0.236)\end{array}$ & $\begin{array}{l}0.673 \\
(0.234)\end{array}$ & $\begin{array}{l}1.835^{* *} \\
(0.386)\end{array}$ & $\begin{array}{l}1.964 * * \\
(0.484)\end{array}$ \\
\hline \multicolumn{7}{|c|}{ Father's education (ref. illiterate) } \\
\hline \multicolumn{2}{|l|}{ Primary } & $\begin{array}{l}1.288 \\
(0.288)\end{array}$ & & $\begin{array}{l}0.905 \\
(0.184)\end{array}$ & & $\begin{array}{l}0.831 \\
(0.163)\end{array}$ \\
\hline \multicolumn{2}{|c|}{ Secondary and above } & $\begin{array}{l}1.078 \\
(0.325)\end{array}$ & & $\begin{array}{l}1.156 \\
(0.261)\end{array}$ & & $\begin{array}{l}0.844 \\
(0.162)\end{array}$ \\
\hline \multicolumn{7}{|c|}{ Father's CCP membership (ref. non-member) } \\
\hline \multicolumn{2}{|l|}{ CCP member } & $\begin{array}{l}0.945 \\
(0.270)\end{array}$ & & $\begin{array}{l}0.978 \\
(0.254)\end{array}$ & & $\begin{array}{l}1.099 \\
(0.253)\end{array}$ \\
\hline Ethnicity & & $\begin{array}{l}1.279 \\
(0.633)\end{array}$ & & $\begin{array}{l}0.874 \\
(0.226)\end{array}$ & & $\begin{array}{l}0.903 \\
(0.201)\end{array}$ \\
\hline \multicolumn{7}{|c|}{ Hukou status at 12 years old (ref. rural hukou) } \\
\hline & & $\begin{array}{l}1.592 \\
(0.437)\end{array}$ & & $\begin{array}{l}1.212 \\
(0.296)\end{array}$ & & $\begin{array}{l}1.123 \\
(0.224)\end{array}$ \\
\hline \multicolumn{7}{|l|}{ Provincial } \\
\hline GDP & & $\begin{array}{l}1.769 \\
(0.640)\end{array}$ & & $\begin{array}{l}2.121^{*} \\
(0.667)\end{array}$ & & $\begin{array}{l}2.248^{* *} \\
(0.578)\end{array}$ \\
\hline Age & & $\begin{array}{l}0.910 * * * \\
(0.019)\end{array}$ & & $\begin{array}{l}0.883 * * * \\
(0.020)\end{array}$ & & $\begin{array}{l}0.923 * * * \\
(0.016)\end{array}$ \\
\hline \multicolumn{7}{|c|}{ Panel wave (ref. wave 2010) } \\
\hline Wave 2012 & & $\begin{array}{l}1.257^{*} \\
(0.146)\end{array}$ & & $\begin{array}{l}1.089 \\
(0.098)\end{array}$ & & $\begin{array}{l}0.993 \\
(0.083)\end{array}$ \\
\hline Wave 2014 & & $\begin{array}{l}1.401 \\
(0.242)\end{array}$ & & $\begin{array}{l}1.286 \\
(0.197)\end{array}$ & & $\begin{array}{l}1.011 \\
(0.126)\end{array}$ \\
\hline Wave 2016 & & $\begin{array}{l}1.523^{*} \\
(0.299)\end{array}$ & & $\begin{array}{l}1.453 * \\
(0.272)\end{array}$ & & $\begin{array}{l}1.093 \\
(0.166)\end{array}$ \\
\hline Constant & $\begin{array}{l}0.075^{* * *} \\
(0.011)\end{array}$ & $\begin{array}{l}2.161 \\
(2.082)\end{array}$ & $\begin{array}{l}0.158^{* * *} \\
(0.023)\end{array}$ & $\begin{array}{l}10.72^{* *} \\
(8.581) \\
\end{array}$ & $\begin{array}{l}0.405 * * * \\
(0.057)\end{array}$ & $\begin{array}{l}2.743 \\
(1.427)\end{array}$ \\
\hline Observations & 11782 & 11782 & 6485 & 6485 & 5425 & 5425 \\
\hline
\end{tabular}

Exponentiated coefficients; Robust standard errors in parentheses; ref. $=$ reference

$* \mathrm{p}<0.05 * * \mathrm{p}<0.01 * * * \mathrm{p}<0.001$

Source: Pooled Data from CFPS 2010-2016. Notes: Results are weighted using cross-sectional weight. 
Figure 4. Predicted Premarital Cohabitation Probability for Married Males and Females Across Educational Levels in Post-reform China

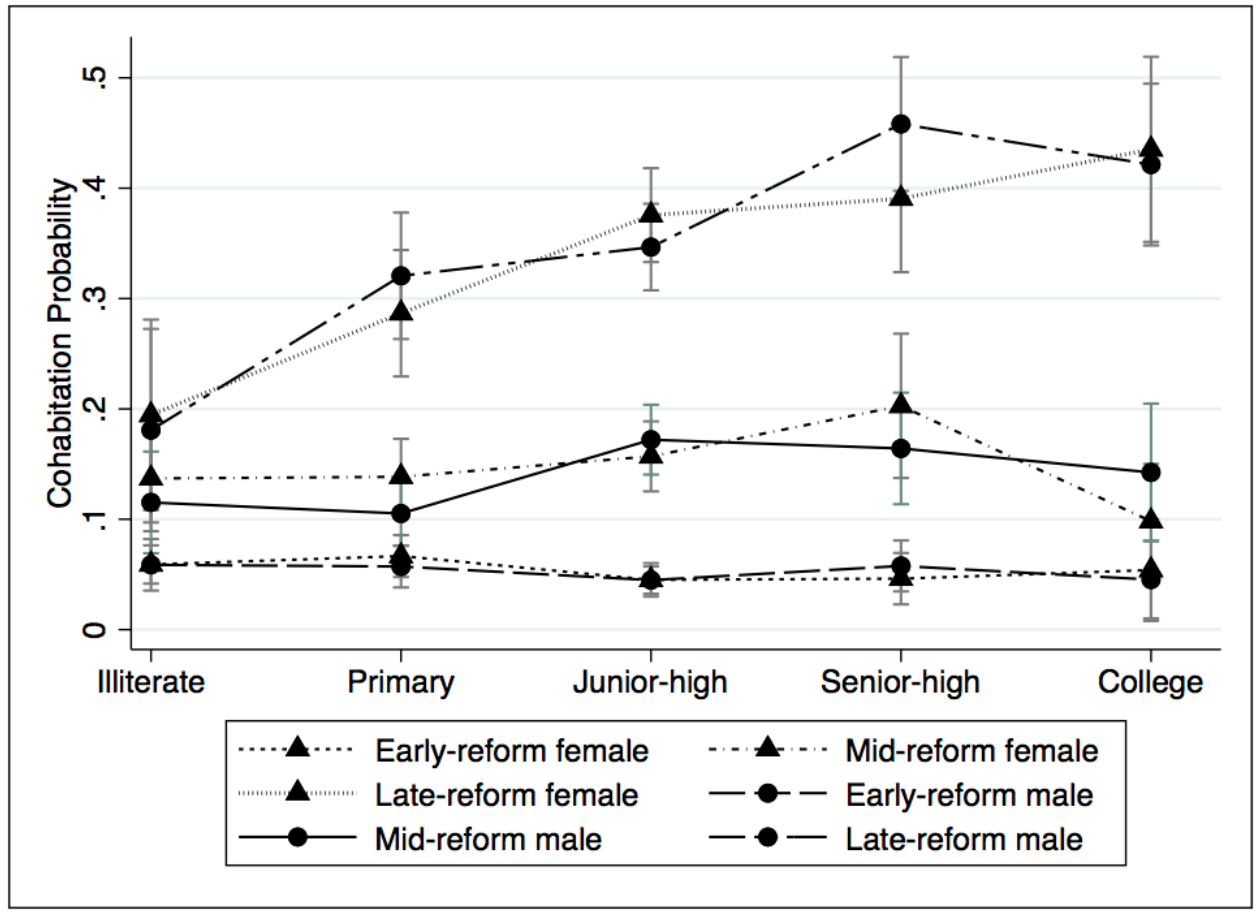

Source: Pooled Data from CFPS 2010-2016.

Notes: Results are weighted using cross-sectional weight and presented with $95 \%$ confidence intervals.

Tables 3 and 4 present the logistic regression results for men and women respectively. In both tables, the estimated odds ratios of the logistic model are presented separately for the early-reform, mid-reform, and late-reform marriage cohorts. The odds ratio shows the change of odds of cohabitation given a unit change of independent variables. Figures 4 presents the predicted probabilities of cohabitation for males and females. Although the results support the suggestion that the association of education and premarital cohabitation changes over time, the direction is opposite to what the hypothesis suggests.

In the early-reform period, no significant relationship is found between education and cohabitation probability for both men and women. One possible reason is that in this period, education level was generally low for both men and women, with the mean years of 
education being 6-8 years for men and less than 6 years for women (see Figure 1). Therefore, the differential effect of educational levels is not obvious.

In the mid-reform era, education has a significant association with men's choice to cohabit, with both junior-high and senior-high school education levels having a significant association with cohabitation for men. Compared to primary school educated men, the odds of male junior-high and senior-high school graduates cohabiting before marriage are $79.5 \%$ and $69.3 \%$ higher respectively. Contrary to men, education has a delayed effect on women in terms of their choice to cohabit. Although the odds of senior-high school educated females cohabiting is $67.8 \%$ higher than their primary school educated counterparts in the raw model, the significance disappears after the confounding factors are controlled for. This might be due to the reason that when cohabitation percentage was still relatively low in society (less than $10 \%$ according to figure 2 and 3 ), there was a stronger social stigma associated with women cohabiting than men. Thus better-educated females would continue to choose a more traditional pathway to marriage just like their less-educated counterparts, despite the ideational changes education might have brought about.

The decreasing effect of college education for men and women is surprising, considering that education level has consistently raised the percentage of cohabitation till college level. This is different from Hypothesis 1, which proposes a consistent positive association between educational attainment and premarital cohabitation. There are two possible reasons for this. First, higher education may be related to higher family status and higher family control because of more substantial family financial investment. Thus, union formation is under stronger control of family compared to others. Second, better education is related to higher social and political capital in China, and college graduates are more likely to be CCP Members (Xie \& Zhang, 2017). Since the Communist Party considered premarital sex and cohabitation as immoral under the socialist regime (Yu \& Xie, 2015) and it still 
carries out a background check for its members, the CCP membership is likely to reduce the occurrence of premarital cohabitation. Nevertheless, further research may be required to determine the reasons why college education is associated with a reduced likelihood of cohabitation for both men and women in this period.

For the most recent marriage cohort, education is a significant predictor of cohabitation for both men and women, even after confounding factors are controlled for. For men, better educational attainment has a positive association with cohabitation, but this positive association peaks at senior-high school. Illiteracy men have 53.5\% lower odds cohabiting than those who have primary school education. In contrast, senior high school and college graduates have $80.8 \%$ and $55.3 \%$ higher odds cohabiting respectively compared to the same group.

For women, educational attainment is a consistent positive predictor of cohabitation (i.e. the higher the education level, the higher the odds of cohabiting before marriage). Senior-high school, for example, associates with $63.5 \%$ higher odds of cohabitation than primary school, while junior-high school education associates with $51.3 \%$ higher odds. College education has the highest positive association, with the odds of cohabitation being $96.4 \%$ higher, almost twice the odds of primary school educated females. This could be due to increasing gender discrimination in the labour market in recent years, which increases the opportunity cost for women to enter into marriage. Thus, highly educated women may delay marriage and substitute it with cohabitation for a period, which requires lower commitment than marriage. The results in the late-reform cohort suggest that the positive association between premarital cohabitation and education is more evident for women than men, which support Hypothesis 3.

In summary, the association between education and cohabitation exhibits different patterns for men and women and this pattern changes over time. The direction of change is 
opposite to what Hypothesis 2 suggests. In the early-reform era, education has no significant association with cohabitation for both men and women. When it reaches the mid-reform era, while education is a strong positive predictor for men, it has a delayed effect on women. However, the positive association for men does not go beyond the senior high school level. In the late-reform era, better educational attainment (until college level) consistently increases the odds of women cohabiting, whilst the positive association for men peaks at senior high school education. The stronger positive association of education in the late-reform era for women than man shows that male cohabitors are not as positively selected as women, which may indicate a possibility of educational hypogamous relationship in marriages preceded by cohabitation, meaning that wives have higher educational achievement than husbands.

\section{CONCLUSION}

The focus of this study is to examine the association between education and premarital cohabitation, how it changes over time and differs between genders. While this study finds no significant association between education and cohabitation for both men and women in the early-reform cohort, this changed in the more recent cohorts. In the mid-reform cohort, secondary education is found to have a significant association with men's choice to cohabit. In contrast, there is a delayed effect of education on cohabitation for women. As for the most recent cohort, education is positively associated with cohabitation for both men and women, and this association is more consistent for women than men.

Therefore, the above results generate the following findings. First, unlike the patterns that have been discovered in most Western countries, there exists a positive association between education and premarital cohabitation in China (Yu \& Xie, 2015). This is consistent with previous literature on this topic in China. Second, the positive association between education and premarital cohabitation is more evident in the recent marriage cohort and more 
consistent for women than men. Contrary to what has been predicted by previous literature in China (Yu \& Xie, 2015), instead of having a positive association at first and then decreasing over time, educational attainment has become an increasingly positive predictor of cohabitation in China for both men and women across marriage cohorts. These results show a different story compared to what the diffusion theory suggests and contrasts with the empirical findings in Western countries. As cohabitors become increasingly negatively selected in Western countries, the results of this research show that the opposite trend is happening in China.

The increasingly positive association between education and premarital cohabitation in China may be because cohabitation is still not yet wholly acceptable in China; thus only better educated people pioneer this behaviour as a result of being influenced by individual and non-traditional family values brought about through better education. The stronger positive association between education and cohabitation for women than men may indicate a disadvantaged position for women in post-reform China. With the resurgence of gender inequality in both domestic and professional space in post-reform China, better educated women face higher opportunity costs in forming families and bearing children. Therefore, they may be more likely to choose cohabitation, which requires less commitment than marriage.

As suggested by the diffusion theory, the association between education and premarital cohabitation not only varies between different political and cultural contexts, but also evolves as the institutional structure in a particular society changes. The mixed results discovered in this study reflect a fundamental difference in the institutional context between China and Western countries, and indicate that China might be developing different demographical patterns and trends compared to Western countries. If the study of cohabitation is any indication, it shows that China has not experienced some key changes 
associated with the second demographical transition, such as alternative arrangements of marriage, gender egalitarian relationships, or births out of wedlock. It might be the case that China is still at the very early stage of the second demographical transition, but it is unlikely that the changes mentioned above will be observed in the near future considering the institutional constraints, e.g. the requirement of a birth permit (which cannot be obtained outside of marriage) for child-bearing in China. Whether China will eventually follow the same trends observed in Western countries or develop its own path (because of its unique institutional and cultural context) needs to be further investigated when future empirical evidence is available.

Nevertheless, there are some notable limitations with the current study. First, the pathways through which education influences cohabitation have not been examined in detail. Further tests are required to determine how education influences cohabitation through socioeconomic prospect (i.e. the return of education) and ideational values (i.e. gender attitudes).

Another potential limitation is the self-reporting nature of the cohabitation experience. Previous studies (Murphy, 2000) have found a notable underreporting issue with cohabitation. Thus, the CFPS data might underestimate the prevalence of cohabitation in China. For example, the CFPS data shows that about a third of recently married couples have had premarital cohabitation experience. However, the number of reported cases of currently cohabiting couples is extremely low, and it does not reflect the rising trend of cohabitation. This could be because there is still a social stigma attached to cohabitation, which led to cohabitating individuals reporting as being single when asked about their current relationship status. Retrospective questions about cohabitation history may remove the cultural pressure and reduce the under-reporting issue. Therefore, the scope of this research is limited to married individuals and how their educational attainment is related to premarital cohabitation experience, as this is the best quality of data that can be obtained at the moment. While this 
research does not include cohabiting experiences that do not lead to marriage, future research may address this issue when such data becomes available.

\section{REFERENCES}

Axinn, W. G., \& Thornton, A. (1992). The relationship between cohabitation and divorce:

Selectivity or causal influence? Demography, 29(3), 357-374.

Becker GS. 1981. A Treatise on the Family. Cambridge: Harvard University Press.

Bernhardt, E. M. (1993). Fertility and employment. European sociological review, 9(1), 25 -

42.

Bumpass, L., \& Lu, H. H. (2000). Trends in cohabitation and implications for children s family contexts in the United States. Population studies, 54(1), 29-41.

Bumpass, L. L., Sweet, J. A., \& Cherlin, A. (1991). The role of cohabitation in declining rates of marriage. Journal of Marriage and the Family, 913-927.

Bian, Y. (2002). Chinese social stratification and social mobility. Annual review of sociology, 28(1), 91-116.

Caldwell, J. C., \& Caldwell, P. (1987). The cultural context of high fertility in sub-Saharan Africa. Population and development review, 409-437.

Cherlin, A. J. (2004). The deinstitutionalization of American marriage. Journal of marriage and family, 66(4), 848-861.

Currier, C. L. (2008). Investing in the future: The one child policy and reform. Journal of Women, Politics \& Policy, 29(3), 365-393.

Chan, K. W., \& Zhang, L. (1999). The hukou system and rural-urban migration in China: Processes and changes. The China Quarterly, 160, 818-855. 
Cao, Y., \& Hu, C. Y. (2007). Gender and job mobility in postsocialist China: A longitudinal study of job changes in six coastal cities. Social Forces, 85(4), 1535-1560.

Davis, D. S. (2014). Privatization of marriage in post-socialist China. Modern China, 40(6), $551-577$.

Deng, Z., \& Treiman, D. J. (1997). The impact of the cultural revolution on trends in educational attainment in the People's Republic of China. American journal of sociology, 103(2), 391-428.

Fincher, L. H. (2016). Leftover women: The resurgence of gender inequality in China. Zed Books Ltd.

Fu, L. (2010). Sociological Research on Cohabitation. Journal of Hangzhou, 110-127 (in Mandarin)

Giddens, A. (1992) The Transformation of Intimacy. Polity Press, Cambridge. Han, D. (2000). The Unknown Cultural Revolution: Educational Reforms and Their Impact on China's Rural Development. East Asia: History, Politics, Sociology, Culture. A Garland Series. Garland Publishing, Inc., a member of the Taylor \& Francis Group, 7625 Empire Drive, Florence, KY 41042-2919.

Hauser, S. M., \& Xie, Y. (2005). Temporal and regional variation in earnings inequality: Urban China in transition between 1988 and 1995. Social Science Research, 34(1), 44-79. Hughes, J., \& Maurer-Fazio, M. (2002). Effects of marriage, education and occupation on the female/male wage gap in China. Pacific Economic Review, 7(1), 137-156.

Hoem, J. M. (1986). The impact of education on modern family-union initiation. European Journal of Population, 2(2), 113-133.

Heuveline, P., \& Timberlake, J. M. (2004). The role of cohabitation in family formation: The United States in comparative perspective. Journal of marriage and family, 66(5), 1214-1230. 
Hare-Mustin, R. T. (1982). China's Marriage Law: a model for family responsibilities and relationships. Family process, 21(4), 477-481.

Ikamari, L. D. (2005). The effect of education on the timing of marriage in Kenya.

Demographic research, 12, 1-28.

Inglehart, R., \& Norris, P. (2003). Rising tide: Gender equality and cultural change around the world. Cambridge University Press.

Jones, G. W. (2007). Delayed marriage and very low fertility in Pacific Asia. Population and Development Review, 33(3), 453-478.

Khan, A. R. (1996). Impact of Recent Macroeconomic and Sectoral Changes on the Poor and Women in China. International Labour Organization.

Kiernan, K. (2001). The rise of cohabitation and childbearing outside marriage in Western Europe. International journal of law, policy and the family, 15(1), 1-21.

Kiernan, K. (2004). Unmarried cohabitation and parenthood in Britain and Europe. Law \& Policy, 26(1), 33-55.

Li, T., \& Zhang, J. (2010). What determines employment opportunity for college graduates in China after higher education reform? China Economic Review, 21(1), 38-50.

Lesthaeghe, R. (1983). A century of demographic and cultural change in Western Europe: An exploration of underlying dimensions. Population and development Review, 411-435.

Lesthaeghe, R. (2010). The unfolding story of the second demographic transition. Population and development review, 36(2), 211-251.

Ma, L., \& Rizzi, E. (2017). Entry into first marriage in China. Demographic Research, 37, $1231-1244$.

Manting, D. (1996). The changing meaning of cohabitation and marriage. European sociological review, 12(1), 53-65. 
Murphy, M. (2000). The evolution of cohabitation in Britain, 1960-95. Population Studies, $54(1), 43-56$.

Mu, Z., \& Xie, Y. (2014). Marital age homogamy in China: A reversal of trend in the reform era?. Social science research, 44, 141-157.

Naughton, B. (2008). A political economy of China's economic transition. China's great economic transformation, 91-135. Cambridge University Press.

Ní Bhrolcháin, M., \& Beaujouan, É. (2013). Education and cohabitation in Britain: A return to traditional patterns? Population and Development Review, 39(3), 441-458.

Oppenheimer, V. K. (1997). Women's employment and the gain to marriage: The specialization and trading model. Annual review of sociology, 23(1), 431-453.

Oppenheimer, V. K. (1988). A theory of marriage timing. American journal of sociology, 94(3), 563-591.

Palmer, M. (1995). The re-emergence of family law in post-Mao China: Marriage, divorce and reproduction. The China Quarterly, 141, 110-134.

Qian, Y., \& Qian, Z. (2014). The gender divide in urban China: Singlehood and assortative mating by age and education. Demographic Research, 31, 1337-1364.

Raymo, J. M., Iwasawa, M., \& Bumpass, L. (2009). Cohabitation and family formation in Japan. Demography, 46(4), 785-803.

Rindfuss, R. R., \& VandenHeuvel, A. (1990). Cohabitation: A precursor to marriage or an alternative to being single? Population and development review, 703-726.

Smock, P. J. (2000). Cohabitation in the United States: An appraisal of research themes, findings, and implications. Annual review of Sociology, 26(1), 1-20.

Shu, X., \& Bian, Y. (2003). Market transition and gender gap in earnings in urban China. Social Forces, 81(4), 1107-1145. 
Shu, X. (2004). Education and gender egalitarianism: The case of China. Sociology of Education, 77(4), 311-336.

Thornton, A., Axinn, W. G., \& Teachman, J. D. (1995). The influence of school enrollment and accumulation on cohabitation and marriage in early adulthood. American Sociological Review, 762-774.

Thornton, A. (1988). Cohabitation and marriage in the 1980s. Demography, 25(4), 497-508.

Thomson, E., \& Bernhardt, E. (2010). Education, values, and cohabitation in Sweden. Marriage \& Family Review, 46(1-2), 1-21.

Wolf, M. (1984). Marriage, family, and the state in contemporary China. Pacific Affairs, $57(2), 213-236$.

Wu, B., \& Zheng, Y. (2008). Expansion of higher education in China: Challenges and implications. The University of Nottingham, China Policy Institute, Briefing Series, 36. Xie, G., \& Zhang, Y. (2017). Seeking out the Party: A study of the Communist Party of China's membership recruitment among Chinese college students. Chinese Journal of Sociology, 3(1), 98-134.

Xie, Y. (2013). Gender and family in contemporary China. University of Michigan, Institute for Social Research, 1-10.

Xie, Y., \& Hu, J. (2014). An introduction to the China family panel studies (CFPS). Chinese Sociological Review, 47(1), 3-29.

Xie, Y. (2016). Understanding inequality in China. Chinese Journal of Sociology, 2(3), 327347.

Yan, Y. (2010). The Chinese path to individualization. The British journal of sociology, 61(3), 489-512.

Yeung, W. J. J. (2013). Higher education expansion and social stratification in China. Chinese Sociological Review, 45(4), 54-80. 
Yu, J., \& Xie, Y. (2015). Cohabitation in China: Trends and determinants. Population and development review, 41(4), 607-628.

Zhang, T., \& Minxia, Z. (2006). Universalizing nine-year compulsory education for poverty reduction in rural China. International review of education, 52(3-4), 261-286.

Zhang, J., Zhao, Y., Park, A., \& Song, X. (2005). Economic returns to schooling in urban China, 1988 to 2001. Journal of comparative economics, 33(4), 730-752.

Zhao, W., \& Zhou, X. (2002). Institutional transformation and returns to education in urban China: An empirical assessment. Research in Social Stratification and Mobility, 19, 339-375. Zheng, W., Zhou, X., Zhou, C., Liu, W., Li, L., \& Hesketh, T. (2011). Detraditionalisation and attitudes to sex outside marriage in China. Culture, health \& sexuality, 13(05), 497-511. 